\title{
A Safe Subarachnoid Block in Idiopathic Thrombocytopenic Purpura with Severe Thrombocytopenia
}

\author{
Tjokorda Gde Agung Senapathi, Christopher Ryalino*, Adinda Putra Pradhana \\ Department of Anesthesia and Intensive Care, Faculty of Medicine, Udayana University, Denpasar 80232, Bali, Indonesia
}

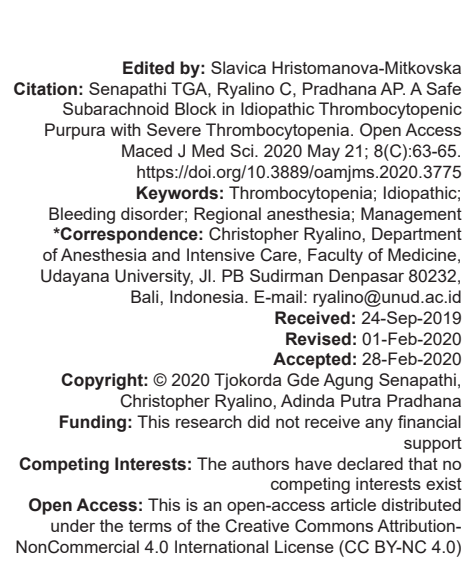

Introduction

Idiopathic thrombocytopenic purpura (ITP) is a situation that can lead easily or excessive hemorrhage. The hemorrhage or bleeding results from abnormally low levels of platelets. It is also called immune thrombocytopenia and affects both children and adults. ITP is an autoimmune ailment characterized by a low platelet count and no abnormality found in the bone marrow. Those with ITP who underwent surgery are considered to have an increased risk for post-operative complications due to the low platelet count [1]

ITP presents in about 1-2 in every 10,000 pregnancies and characterized by the presence of autoantibodies that bind to platelet antigens, destroys the platelets in the reticuloendothelial system causing thrombocytopenia [2]. The American College of Obstetrics and Gynecology (ACOG) stated that some elements are conventionally correlated with this disease: (1) Platelet count $<100 \times 10^{3} / \mathrm{uL}$ with or without megakaryocytes, (2) the absence of other systemic conditions or drugs that are associated with thrombocytopenia, (3) a normal or increased medullary megakaryocytes, and (4) the absence of splenomegaly [3].

\section{Case Presentation}

A $65 \mathrm{~kg}, 36$-year-old woman with a history of ITP was planned for an elective ovarian cyst removal procedure. She was scheduled for a similar procedure at another hospital before she was admitted to our hospital, but the blood transfusions were given never managed to get her platelet count up. She was first diagnosed with ITP in 2015, after a C-section surgery that caused her $1500 \mathrm{~mL}$ amount of bleeding, and she was admitted to the ICU for 3 days before she was transferred to a regular ward. She never experienced excessive bleeding after that but said that she easily gets bruises, especially on her extremities, which will resolve within days or a couple of weeks.

Her ITP history aside, she presented with normal findings except for her blood count. Two days before surgery, her CBC came back with white blood cell $12.29 \times 10^{3} / \mu \mathrm{L}$, hemoglobin $11.5 \mathrm{~g} / \mathrm{dL}$, hematocrit $36.4 \%$, and platelet $9 \times 10^{3} / \mu \mathrm{L}$. We gave $300 \mathrm{~mL}$ of fresh frozen plasma and $1000 \mathrm{~mL}$ of thrombocyte concentrate, and we retake the blood test $24 \mathrm{~h}$ after. The results came back as white blood cell $14.71 \times 10^{3} / \mu \mathrm{L}$, hemoglobin $11.8 \mathrm{~g} / \mathrm{dL}$, hematocrit $37.6 \%$, and platelet $15 \times 10^{3} / \mu \mathrm{L}$. Other laboratory results were bleeding time 
(3 min), clotting time (12 $\mathrm{min})$, prothrombin time $(\mathrm{PT})=$ $13.6 \mathrm{~s}$, activated partial thromboplastin time $(\mathrm{aPTT})=$ $31.5 \mathrm{~s}$, and INR 1.01.

Considered that, she did not respond as well during previous transfusions, we explained the situations to the patient and her family, and we decided to go on with the surgery. We prepared a subarachnoid block with a G27 spinal needle without introducer assistance.

Premedication used was $4 \mathrm{mg}$ ondansetron, $125 \mathrm{mg}$ methylprednisolone, and $2 \mathrm{mg}$ midazolam, all intravenously. While lying on her left side, we administered $12.5 \mathrm{mg}$ of intrathecal $0.5 \%$ heavy bupivacaine without any additional medications. The surgery went uneventful except for $1300 \mathrm{~mL}$ bleeding without any drop in hemodynamics. During surgery, we administered a total of $1200 \mathrm{~mL}$ crystalloid and $500 \mathrm{~mL}$ colloid, with $1000 \mathrm{mg}$ tranexamic acid. After the surgery, she was transferred to ICU, received a $750 \mathrm{~mL}$ blood transfusion in $48 \mathrm{~h}$, then she was discharged to ward. She was discharged home on the $4^{\text {th }}$ day after the surgery and reported no complaints on her follow-up visit at the outpatient department.

\section{Discussion}

Perioperative hemorrhage in patients with low platelet counts presents a specific surgical challenge. The bleeding time of ITP patients is generally shorter compared to the severity of the thrombocytopenia, and the severity of bleeding in ITP is less than that encountered with equivalent degrees of thrombocytopenia in bone marrow failure. Several methods have been proposed to elevate the pre-operative platelet count to the "safe" level.

Severely low platelet count requires platelet transfusion before surgery. In advanced medical centers, IV immunoglobulins (IVIg) may be available. IVIg is an essential agent in the pre-operative period of an elective procedure, although this approach is not always practical [1]. IVIg that is given in a dose of $1 \mathrm{~g} / \mathrm{kg}$ reduces platelet destruction [4]. A significant increase in the platelet count is usually not achieved until 2-3 days following initiation of therapy. IVIg is also useful in the post-operative period. Besides, its relatively high price, the possibility of its side effects (allergic response, liver dysfunction, etc.,) must also be considered.

Several authors reported various anesthesia management in thrombocytopenic patients, by both general [4], [5], [6], [7], [8] and regional [9] anesthesia. We approached this case by regional anesthesia for two reasons. First, the patient received a platelet transfusion before she was admitted to our hospital. Her platelet level was moving slightly $15,000 / u L-21,000 / u L$ and then went down to $11,000 / \mathrm{uL}$. That means she was not responding well to platelet transfusion. She was diagnosed with an ovarian cyst which causing intermittent pain, and the pain was disturbing her quality of life. She went to seek help from a gynecologist in the hope that doctors will do something to alleviate the pain. Second, her coagulation profile was somehow returned to our satisfaction (PT $13.6 \mathrm{sec}$, aPTT $31.5 \mathrm{sec}$, and INR 1.01).

We prepared this case with a $1000 \mathrm{~mL}$ of PRCs and $1000 \mathrm{~mL}$ of platelet transfusions. We used a G27 spinal needle to reduce the chance of encountering blood vessels during the subarachnoid block procedure that may create certain complications for the patient. The spinal needle was inserted without introducer for the same reason. Without it, the insertion was somewhat more difficult, of course, but considering the risks the needle brings to the patient, we thought that it was thoughtful.

General anesthesia may be a common option for such a case, but it is not without any potential complications. Given the fact that the patient was bruising easily in her daily life, there is always a chance that we will cause direct trauma to her airway during laryngoscopy. We all agreed that general anesthesia is not a bad choice for this case, but given her current coagulation status, we were assured that regional anesthesia is a safer option. Despite some recommendations stated that platelet count of $<100$ is safe for spinal anesthesia, there is currently no consistent evidence of a safe platelet count for spinal anesthesia [10].

\section{Conclusion}

The administration of IVIg is not mandatory for the pre-operative management of ITP. Platelet transfusions are necessary for pre-operative management of emergency surgical treatment for patients with thrombocytopenia. Both PRC and platelet transfusions are essential to be prepared before surgery. Anesthetists should be able to manage ITP patients by both general or regional anesthesia. A thorough understanding of risks and benefits of both techniques may lead anesthetists to better judgment and, eventually, a safer and better outcome for the patient.

\section{Acknowledgment}

The authors report no conflicts of interest in this case report. 


\section{References}

1. Toyomasu $\mathrm{Y}$, Shimabukuro $\mathrm{R}$, Moriyama H, Eguchi $\mathrm{D}$, Ishikawa K, Kishihara $\mathrm{F}$, et al. Successful perioperative management of a patient with idiopathic thrombocytopenic purpura undergoing emergent appendectomy: Report of a case. Int J Surg Case Rep. 2013;4:898-900. https://doi.org/10.1016/j. ijscr.2013.05.019

PMid:23978533

2. British Committee for Standards in Haematology General Haematology Task Force, Guidelines for the investigation and management of idiopathic thrombocytopenic purpura in adults, children and in pregnancy. Br J Haematol. 2003;120(4):574-96. https://doi.org/10.1046/j.1365-2141.2003.04131.x

3. Ben S, Rodriguez F, Severo C, Debat N. A case of HELLP syndrome in a patient with immune thrombocytopenic purpura. Obstet Gynecol Int. 2010;2010:692163. https://doi. org/10.1155/2010/692163

4. WajekarAS. Anaesthesia management of a patient with idiopathic thrombocytopenic purpura with antepartum haemorrhage for emergency caesarean section. Indian J Anaesth. 2015;59(10):689-90. https://doi.org/10.4103/0019-5049.167474 PMid:26644625

5. Özbilgin S, Balkan BK, Şaşmaz B. Anaesthesia for caesarean section of pregnant women with idiopathic thrombocytopenic purpura. Turk J Anaesth Reanim. 2013;41(5):175-7. https://doi. org/10.5152/tjar.2013.21

\section{PMid:27366365}

6. Suparna M, Rudra PA, Jyotsna G. Anaesthesia management of patient with idiopathic thrombocytopenic purpura a case series. J Anesth Ter. 2018;1:105.

7. Takabayashi R, Nishikido O, Nagano K, Doi A, Nishisako R, Tateda T. Anesthetic management for cesarean delivery in a patient with May-Hegglin anomaly. Masui. 2007;56(10):1198-9.

8. Kumemura M, Omae T, Kou K, Sakuraba S, Niimi N, Kunishima S. Anesthetic management without perioperative platelet transfusion for cervical laminectomy and laminoplasty in a case of May-Hegglin anomaly. J Anesth. 2018;32(4):641-4. https://doi.org/10.1007/s00540-018-2522-8 PMid:29934660

9. Muzannara AM, Al Harbi M, Rathore R, Tawfeeq N, Wambi F, Mahmood N, et al. Epidural anesthesia for labor and delivery in a patient with May Hegglin anomaly: A case report. Local Reg Anesth. 2017;10:53-8. https://doi.org/10.2147//ra.s125811 PMid:28496360

10. Ozelo MC, Colella MP, de Paula EV, do NascimentoAC, Villac PR, Bernardo WM. Guideline on immune thrombocytopenia in adults: Associac,ão brasileira de hematologia, hemoterapia e terapia celular. Project guidelines: Associac,ão Médica Brasileira 2018. Hematol Transfus Cell Ther. 2018;40(1):50-74. https://doi.org/10.1016/j.htct.2017.11.001 